\title{
SOURCES OF ECONOMICAL GROWTH IN THE CZECH FOOD PROCESSING
}

\author{
Lukáš Čechura, Heinrich Hockmann*
}

\begin{abstract}
:
The paper attempts to assess the development path of the Czech food processing and to identify the presence of idiosyncratic developments in industries. We elaborate it by using a fitted production function for the construction of TFP and by decomposing TFP into a scale effect, a technical change effect and an efficiency effect for total food processing and its selected branches. The results suggest that despite more than one decade of transition, serious adjustment problems exist, including problems on the capital market. Furthermore, contrary to the large differences among firms in the whole sample, the various sectors are rather homogeneous. TFP shows that although individual sectors have a few frontrunners, the majority of companies perform quite poorly. The scale effect is relatively small in food processing. Technical change has contributed positively to TFP in recent years, and the efficiency effect varies rather strongly. Whereas scale effect and technical change have a similar pattern across industries, the efficiency effect differs significantly. There is also some indication that the efficiency effect is affected by different sources. Finally, in addition to systemic effects, industry developments are characterized by idiosyncratic factors, especially in the Dairy industry.
\end{abstract}

Keywords: Czech Republic, food processing, transition, TFP (Total Factor Productivity), efficiency, SFA (Stochastic Frontier Analysis)

JEL Classification: D 24, O 12, P 27

\section{Introduction}

The agrarian sector in Central and Eastern Europe experienced a couple of important institutional and economic changes in the last two decades. The elements and results of these transitional processes have been deeply analysed and evaluated in many papers, employing different analytical approaches. A typical feature of these analyses and studies has been a focus on the agricultural sector (see for instance Backus et al., 2006; Curtiss, 2002; Hockmann et al., 2007; Munroe; 2001). However, the importance

* Lukáš Čechura, Department of Agricultural Economics, Czech University of Live Sciences, Kamýcká 129, CZ - 165 21, Praha 6 - Suchdol (cechura@pef.czu.cz); Heinrich Hockmann, Leibniz-Institute of Agricultural Development in Central and Eastern Europe (IAMO), TheodorLieser-Straße 2, 06120 Halle (Saale), Germany (hockmann@iamo.de). The research was supported by the Ministry of Education, Youth and Sports of the Czech Republic (Grant No. MSM 6046070906). 
of interactions between the stages of the value chain demands a consideration of the whole value chain, by identifying the factors which determine the successful or failed growth of the agrarian sector. In this regard, the food processing industry has received surprisingly limited interest from empirical analysts (a few examples include Wandel, Hartmann, 1999 and Jansik, 2002).

The institutional and economic changes which have occurred in the Czech food processing industry can be divided into three periods. The first half of the Nineties of the 20th century was characterized, in particular, by the establishment of institutions necessary for running a market economy, and by changes in ownership. In this period, nearly all important state companies were privatized. The second period, from the end of the Nineties until the entrance of the Czech Republic into the EU, saw the modernisation and enlargement of some processing capacities. The food processing companies had to modernize their production, due to the acquisition of acquis communautaire in advance of the EU enlargement. The new standards forced financially poor companies to drop out of the market. In the last period, i.e. after the EU enlargement, processing companies have been operating on the common market. That is, tariffs and other barriers were removed by the entrance of the Czech Republic into the EU, which resulted in a significant increase in both the export and import of food products.

The basic figures describing the development of the Czech food processing industry in the last two decades are as follows. The production of the food processing industry in 1995 (according to data for companies with 100 or more employees) was nearly identical to the production in 1990. In addition, neither the number of employees nor the labour productivity changed significantly between the years 1990 and 1995. Moreover, the food processing industry retained its importance within the structure of the processing industry in this period. After 1995 the total production of the food processing industry oscillated around the level of CZK 295 bn (in constant prices, $2005=100$ ). The changes in production were significantly determined by both exports and imports, especially following the EU enlargement. The increasing trend of import has exceeded the increasing export trend in Slaughtering, fruit and vegetable processing, and the Milling industry. Thus, we can assume that there are problems with the competitiveness of less efficient firms in these industries. Since the added value showed an increasing trend and the number of employees a decreasing one, labour productivity went up from 0.32 (added value in mil. CZK per employee) in 1995 to 0.54 in 2007. Investment dropped from CZK 17.75 bn in 1995 (in constant prices, $2005=100$ ) to CZK 12.27 bn in 2000, and then went up again. In 2006, investment reached $90.5 \%$ of its level in 1995. Capital intensity stagnated between the years 1995 and 2007, and the ratio of added value to capital increased from 0.17 in 1995 to 0.29 in 2007. The structure of the food processing industry did not change significantly between the years 1995 and 2007.

In this paper we deal with the Czech food processing and analyse how its performance developed in the second and third above-mentioned period of institutional and economic change, i.e. before and after the entrance of the Czech Republic into the EU. In particular, we focus on the development of total factor productivity (TFP). TFP is decomposed into a scale effect (SE), a technical change effect (TCE) and an efficiency effect (TE). SE captures influences resulting from changes in the intensity 
of factor use. The TCE tells us about how innovative activities have changed the production process, and provides information on whether the sector has entered a development path leading to long-term growth. TE can be regarded as the impact of unused capacities on productivity. It can be assumed that TE will be especially severe when the institutional and economic environment undergoes changes which induce significant adjustments in the organisation and input structure of a company. In this interpretation, TE is the static complement of adjustment costs in a dynamic framework.

Two main questions will be elaborated. The first relates to the impacts of TCE and TE. The aim is to assess whether there is any indication that the sector is following a path of sustainable development, characterized by the development and adoption of innovation and by the reduced waste of resources due to inefficient input use. The second question concerns sector-specific development, especially whether the challenges and adjustments are systemic, i.e. the same for all branches, or whether idiosyncratic developments occurred.

We will elaborate on these questions by estimating a production function for the Czech food processing. The estimates will be used to construct TFP and the contribution of the three effects mentioned above. These calculations will be conducted for total food processing as well as for selected branches from the first processing stage: Slaughtering, the Dairy industry, Milling and Feed production.

The paper is organized as follows. Chapter 2 provides the theoretical background of our estimation procedure. The database is discussed in the following chapter. All empirical results are presented and discussed in Chapter 4, while Chapter 5 provides a comparative assessment of the findings for the different sectors.

\section{Theoretical Background and Empirical Implementation}

We assume that the production possibilities can be approximated by a frontier production function:

$$
y_{i t}=a_{i} f\left(t, \boldsymbol{x}_{i t} ; \boldsymbol{\beta}\right) T E_{i t}
$$

where $y_{i t}$ and $\boldsymbol{x}_{i t}$ represents output and a vector of inputs, respectively. The subscripts $i$, with $i=1,2, \ldots, \mathrm{N}$, and $t$, with $t=1, \ldots, T$, refer to a certain firm and time (year), respectively. $a_{i}$ and $\boldsymbol{\beta}$ are parameters to be estimated. $a_{i}$ refers to firm-specific (exogenous) productivity levels while $\boldsymbol{\beta}$ determines the production function $f$. The variable $t$ in $f$ captures influences of technical change. Technical efficiency, $T E_{i t}$, with $0<T E_{i t}<1$, captures deviations from the maximum achievable output.

The production possibilities were approximated by a translog function:

$$
\begin{aligned}
\ln f\left(\mathrm{t}, \mathbf{x}_{i t} ; \boldsymbol{\beta}\right) & =\sum_{j=1}^{K} \beta_{j} \ln x_{i j t}+\frac{1}{2} \sum_{j=1}^{K} \sum_{k=1}^{K} \beta_{j k} \ln x_{i j t} \ln x_{i k t}+ \\
+ & \beta_{t} t+\frac{1}{2} \beta_{t t} t^{2}+\sum_{j=1}^{K} \beta_{j t} \ln x_{i j t} t
\end{aligned}
$$

where subscripts $j$ and $k$ refer to a certain input and $K$ represents the total number of inputs employed in the estimation of the frontier production function. 
Diewert (1976) has shown that the Törnquist Theil index (TTI) exactly determines changes in production which result from input adjustments when the underlying production function has the translog from (i.e., changes that are captured by the first line in (2)). Moreover, Caves et al. (1982) showed how the TTI has to be extended to allow for multilateral consistent comparisons. The basic idea is to consider deviation from the sample means in the construction of the index. The input index (1) is given by:

$$
\begin{gathered}
\ln v_{i t}{ }^{V R S}=\frac{1}{2} \sum_{j=1}^{K}\left[\left(\varepsilon_{i t, j_{0}}+\bar{\varepsilon}_{j}\right)\left(\ln x_{i t, j}-\overline{\ln x_{j}}\right)+\bar{\varepsilon}_{j} \overline{\ln x_{j}}-\overline{\varepsilon_{i t, j_{0}} \ln x_{i t, j}}\right] \\
\text { with } \varepsilon_{i t, j_{0}}=\frac{\partial \ln f\left(t, x_{i t, j} ; \boldsymbol{\beta}\right)}{\partial \ln x_{i t, j}}
\end{gathered}
$$

and a bar over a variable specifies the arithmetic mean over all observations. The abbreviation VRS indicates variable returns to scale. If no aggregation is needed because the development of one variable has to be depicted, the index collapses to a simple derivation from the mean of the variables. Thus, in the case of output $(\psi)$ and efficiency $(\varepsilon)$ the indices are:

$$
\ln \psi_{i t}=\ln y_{i t}-\overline{\ln y_{i t}} \text { and } v_{i t}=\ln T E_{i t}-\overline{\ln T E_{i t}},
$$

respectively.

TFP is usually defined as the relation of an output and an input index, where the latter is calculated under the assumption that the underlying technology is characterized by constant returns to scale. The required transformation changes (3) to:

$$
\ln v_{i t}^{c r t}=\frac{1}{2} \sum_{j=1}^{K}\left[\left(\frac{\varepsilon_{i t, j_{0}}}{\sum_{i=1}^{K} \varepsilon_{i t, j_{0}}}+\frac{\bar{\varepsilon}_{j}}{\sum_{i=1}^{K} \varepsilon_{j_{0}}}\right)\left(\ln x_{i t, j}-\overline{\ln x_{j}}\right)+\frac{\bar{\varepsilon}_{j}}{\sum_{i=1}^{K} \varepsilon_{j_{0}}} \overline{\ln x_{j}}-\frac{\overline{\varepsilon_{i t, j_{0}}} \ln x_{i t, j}}{\sum_{i=1}^{K} \varepsilon_{i t, j_{0}}}\right] .
$$

Given these definition, TFP and its decomposition is given by:

$$
\begin{aligned}
\ln T F P_{i t}=\ln \psi_{i t}-\ln v_{i t}^{c r t}= & \ln v_{i t}+\ln v_{i t}+\ln \tau_{i t}, w i t h \ln t_{i t}=\ln v_{i t}^{V R S}-\ln v_{i t}^{c r t} \\
& S E \quad T E T C E
\end{aligned}
$$

The setup of the theoretical background suggests the estimation of a fixed-effect frontier model. In particular, we estimate a model of the form:

$$
\ln y_{i t}=\ln a_{i}+\ln f\left(t, \boldsymbol{x}_{i t} ; \boldsymbol{\beta}\right)-u_{i t}+v_{i t} .
$$

with $u_{i t}=-\ln T E_{i t}$, with $u_{i t}>0 ; v_{i t}$ is a two sided error term capturing stochastic influences (Greene 2002, Kumbhakar and Hjalmarsson 1993). For estimation, $u_{i t}$ and $v_{i t}$ have to be parameterized. We assume that the following distributional assumptions hold:

$$
v_{i t} \sim N\left(0, \sigma_{v}^{2}\right) \text {, and } u_{i t} \sim N^{+}\left(\mu, \sigma_{u}^{2}\right) .
$$


The stochastic frontier function model (7) is estimated using the method of maximum likelihood (ML) and a computer program LIMDEP.

Because of a low number of observations for individual branches in some years, the estimation was conducted for the whole data set. Based on these estimates the various indices $\left(T F P_{i t}, \mathrm{r}_{\mathrm{it}}, v_{\mathrm{it}}\right.$ and $\left.\tau_{\mathrm{it}}\right)$ are estimated.

\section{Data}

The panel data set we use in the econometric analysis is drawn from the database of the Creditinfo Firms' Monitor, collected by Creditinfo Czech Republic, s.r.o. The database contains all registered companies and organisations in the Czech Republic and includes information on final accounts, financial analyses, information about debtors, financial solvency information, etc. As far as final accounts are concerned, it contains over 200,000 final accounts from 1992 to 2007.

In our analysis, we use the final accounts of firms whose main activity is food processing, according to the OKEČ classification (OKEC $\check{C} 15$; OKEC classification of economic activities in the Czech Republic. OKEČ is processed in accordance with the rules for creating sector classifications in member states of the EU). Since not all firms in the database have complete information, we include in our sample only those firms having three or more final accounts in the database over the period 1993-2007, and non-zero and positive values of variables of interest. Thus, we were constrained to using an unbalanced panel data set containing 471 food processing firms with 2,284 observations, representing the period from 1998 to 2007.

Table 1:

Significance of Branches in the Data Set (as a percent of total industry output)

\begin{tabular}{|l|c|c|c|c|c|c|}
\hline & \multirow{2}{*}{$\begin{array}{c}\text { Average } \\
\text { output per } \\
\text { firm (food } \\
\text { industry) }\end{array}$} & \multirow{2}{*}{$\begin{array}{c}\text { Number } \\
\text { of firms }\end{array}$} & & \multicolumn{4}{|c|}{\begin{tabular}{c} 
Share of branch in industry output \\
\cline { 6 - 7 }
\end{tabular}} & & Slaughte- & Dairy & Milling & Feed \\
\hline $\mathbf{1 9 9 8}$ & 329.27 & 15 & & & & \\
\hline $\mathbf{1 9 9 9}$ & 370.06 & 37 & & $28.50 \%$ & & $3.88 \%$ \\
\hline $\mathbf{2 0 0 0}$ & 363.10 & 104 & $5.09 \%$ & $17.78 \%$ & $1.60 \%$ & $3.89 \%$ \\
\hline $\mathbf{2 0 0 1}$ & 361.63 & 239 & $7.73 \%$ & $14.66 \%$ & $4.46 \%$ & $4.46 \%$ \\
\hline $\mathbf{2 0 0 2}$ & 383.35 & 326 & $7.31 \%$ & $14.02 \%$ & $2.83 \%$ & $4.81 \%$ \\
\hline $\mathbf{2 0 0 3}$ & 499.52 & 381 & $6.47 \%$ & $12.91 \%$ & $1.74 \%$ & $3.98 \%$ \\
\hline $\mathbf{2 0 0 4}$ & 348.03 & 434 & $8.42 \%$ & $11.26 \%$ & $2.46 \%$ & $5.33 \%$ \\
\hline $\mathbf{2 0 0 5}$ & 366.57 & 367 & $9.43 \%$ & $14.59 \%$ & $5.93 \%$ & $5.89 \%$ \\
\hline $\mathbf{2 0 0 6}$ & 817.96 & 339 & $1.28 \%$ & $5.77 \%$ & $1.31 \%$ & $4.54 \%$ \\
\hline $\mathbf{2 0 0 7}$ & 465.89 & 39 & $1.95 \%$ & & $4.92 \%$ & $8.46 \%$ \\
\hline
\end{tabular}

Note: in mil. CZK

Source: own calculations. 
Table 1 provides information about the significance of our branches of interest in the dataset. The total share of industry output represented by the analyzed branches is, on average, $26.41 \%$. In 2006, a decline in the shares of all branches might have been caused by the exit and entry of important (large) firms to the branch or to the database. The entry of large firms can be deduced from the significant increase in average output per firm, which is approximately two times higher compared to the previous years. The average shares of individual branches are about 6\% (Slaughtering), 15\% (Dairy), $3.16 \%$ (Milling) and 4\% (Feed). The average number of firms in the sample between 1998 and 2007 was 228, of which 24 were in Slaughtering, 23 in Dairy, 14 in Milling and 17 in Feed.

In the analysis, the following variables were used: output $\left(\mathrm{y}_{\mathrm{it}}\right)$, labour $\left(\mathrm{A}_{\mathrm{it}}\right)$, capital $\left(\mathrm{K}_{\mathrm{it}}\right)$ and inputs $\left(\mathrm{V}_{\mathrm{it}}\right)$. Output represents the total sales of goods, products and services of the firm. Labour input is total personnel costs per firm. Capital represents the book value of tangible assets. Finally, variable inputs were used in the form of total costs of material and energy consumption per firm. Output was deflated by the index of food processing prices $($ December $1999=100)$, labour by CPI $($ December $1999=100)$, capital and inputs by the index of processing prices $(2000=100)$.

Table 2:

Development Indicators of Food Processing and Selected Branches in the Database

\begin{tabular}{|c|c|c|c|c|c|c|c|}
\hline & & $\begin{array}{c}\text { Output } \\
\left(y_{i t}\right)\end{array}$ & $\begin{array}{l}\text { Labour } \\
\left(A_{i t}\right)\end{array}$ & $\begin{array}{c}\text { Capital } \\
\left(\mathrm{K}_{\mathrm{it}}\right)\end{array}$ & $\begin{array}{c}\text { Materials } \\
\left(\mathrm{V}_{\mathrm{it}}\right)\end{array}$ & $\begin{array}{c}\text { Labour } \\
\text { Productivity }\end{array}$ & $\begin{array}{c}\text { Capital } \\
\text { Intensity }\end{array}$ \\
\hline \multirow{2}{*}{ All firms } & 1998 & 329.27 & 42.82 & 143.90 & 206.70 & 7.69 & 3.36 \\
\hline & 2007 & 465.89 & 64.05 & 511.60 & 305.23 & 7.27 & 7.99 \\
\hline \multicolumn{2}{|l|}{ growth rate } & $3.93 \%$ & $4.58 \%$ & $15.13 \%$ & $4.43 \%$ & $-0.62 \%$ & $10.10 \%$ \\
\hline \multirow{2}{*}{ Slaughtering } & 2000 & 384.13 & 38.34 & 105.17 & 298.55 & 10.02 & 2.74 \\
\hline & 2007 & 177.09 & 16.32 & 48.49 & 145.15 & 10.85 & 2.97 \\
\hline \multicolumn{2}{|l|}{ growth rate } & $-10.47 \%$ & $-11.49 \%$ & $-10.47 \%$ & $-9.79 \%$ & $1.14 \%$ & $1.15 \%$ \\
\hline \multirow{2}{*}{ Dairy } & 1999 & 780.57 & 61.78 & 132.63 & 661.23 & 12.64 & 2.15 \\
\hline & 2006 & 640.08 & 36.81 & 91.65 & 549.93 & 17.39 & 2.49 \\
\hline \multicolumn{2}{|l|}{ growth rate } & $-2.79 \%$ & $-7.13 \%$ & $-5.14 \%$ & $-2.60 \%$ & $4.67 \%$ & $2.14 \%$ \\
\hline \multirow{2}{*}{ Milling } & 2000 & 200.97 & 23.52 & 68.36 & 133.42 & 8.55 & 2.91 \\
\hline & 2007 & 297.86 & 28.87 & 93.74 & 232.64 & 10.32 & 3.25 \\
\hline \multicolumn{2}{|l|}{ growth rate } & $5.78 \%$ & $2.97 \%$ & $4.61 \%$ & $8.27 \%$ & $2.73 \%$ & $1.60 \%$ \\
\hline \multirow{2}{*}{ Feed } & 1999 & 265.31 & 31.35 & 110.59 & 199.28 & 8.46 & 3.53 \\
\hline & 2007 & 512.39 & 35.82 & 212.18 & 398.06 & 14.31 & 5.92 \\
\hline \multicolumn{2}{|l|}{ growth rate } & $8.58 \%$ & $1.68 \%$ & $8.49 \%$ & $9.03 \%$ & $6.78 \%$ & $6.69 \%$ \\
\hline
\end{tabular}

Note: Values for each year are in mil. CZK.

Source: own calculations. 
Table 2 shows that in most sectors the average growth rate of output as well as most of the inputs were positive. The exceptions were Dairy and Slaughtering, where a decline in output and inputs could be observed. Despite this, labour productivity and capital intensity increased. A decrease occurred only for average labour productivity in the full sample. The information in Table 2 already suggests that the firms were subject to substantial adjustment processes regarding the structure of inputs, and that this development was mainly driven by investment activities.

\section{Empirical Results}

\subsection{Parameter Estimates}

Table 3 provides parameter estimates for the food industry and for selected sectors. Since the second derivatives of the translog function with respect to the log of input are constant, only the first order effects differ among branches. Signs and magnitudes of the coefficients, as well as the numerical results obtained, were found to be robust even under different model specifications. The criteria of theoretical consistency, i.e., the assumptions regarding slope and curvature of the production function, are fulfilled, at least at the sample mean. All production elasticities are positive; moreover, the necessary condition for quasi-concavity is fulfilled, i.e., we estimated diminishing marginal productivity for each input $\left(\beta_{\mathrm{qq}}+\beta_{\mathrm{q}}{ }^{2}-\beta_{\mathrm{q}}<0\right.$, for $\left.\mathrm{q}=\mathrm{A}, \mathrm{K}, \mathrm{V}\right)$.

The production elasticities of the individual branches have basically the same pattern as the elasticity for the whole sample, with values of about $0.25,0.05$ and 0.70 for labour, capital and variable inputs, respectively. However, the main difference between the full sample and the individual branches is that production elasticities are lower for labour and higher for variable inputs. This corresponds to the selection of the branches. They belong to the first processing stage, in which agricultural raw materials play the central role in the production processes.

For the average firm in the full sample, there is no indication of economies of scale (the sum of the elasticities is about one). In the individual industries, however, returns to scale increase slightly, ranging from about 1.01 in Milling to about 1.05 in the Dairy industry; this result already suggests that the impact of SE on a productivity change will be rather small.

Technical change positively affected $\left(\beta_{\mathrm{T}}>0\right)$ the full sample as well as individual industries. Moreover, the impact of technical change accelerated over time $\left(\beta_{\mathrm{TT}}>0\right)$. Differences regarding technical change among the sectors are more pronounced than in the case of production elasticities. Especially in Milling, firms benefited on average more than in other industries. The lowest impact of technical change was estimated for the Dairy industry. The indication for biased technical change is rather small. Only for capital could a significant factor saving impact be observed. 
Table 3:

Parameter Estimates of the Fixed Effect Model and Parameter Variation by Selected Industries

\begin{tabular}{|c|c|c|c|c|c|}
\hline & All Sectors & Slaughtering & Dairy & Milling & Feed \\
\hline $\boldsymbol{\beta}_{\mathrm{T}}$ & $0.0078^{* *}$ & 0.0083 & 0.0043 & 0.0104 & 0.0066 \\
\hline $\boldsymbol{\beta}_{\mathrm{TT}}$ & $0.0088^{* * *}$ & & & & \\
\hline$\beta_{\mathrm{A}}$ & $0.2563^{* * *}$ & 0.2217 & 0.2217 & 0.2122 & 0.2086 \\
\hline $\boldsymbol{\beta}_{\mathrm{K}}$ & $0.0615^{\star * *}$ & 0.0507 & 0.0386 & 0.0504 & 0.0569 \\
\hline $\boldsymbol{\beta}_{\mathrm{v}}$ & $0.6838^{* * *}$ & 0.7482 & 0.7946 & 0.7460 & 0.7481 \\
\hline$\beta_{\text {AT }}$ & 0.0036 & & & & \\
\hline $\boldsymbol{\beta}_{\mathrm{KT}}$ & $-0.0061^{\star * *}$ & & & & \\
\hline$\beta_{\mathrm{VT}}$ & 0.0002 & & & & \\
\hline$\beta_{\mathrm{AA}}$ & $0.1341^{* * *}$ & & & & \\
\hline $\boldsymbol{\beta}_{\mathrm{KK}}$ & $0.0214^{* * *}$ & & & & \\
\hline$\beta_{\mathrm{vv}}$ & $0.0953^{* * *}$ & & & & \\
\hline$\beta_{\mathrm{AK}}$ & $-0.0244^{* * *}$ & & & & \\
\hline$\beta_{A V}$ & $-0.0543^{* * *}$ & & & & \\
\hline $\boldsymbol{\beta}_{\mathrm{KV}}$ & $-0.0165^{\text {***}}$ & & & & \\
\hline$\sigma$ & $0.9086^{* * *}$ & & & & \\
\hline$\lambda$ & $2.6371^{* * *}$ & & & & \\
\hline
\end{tabular}

Note: The values for the individual branches were calculated as averages over the companies belonging to this group. Source: own calculations.

The period under investigation begins with 1998. It could be expected that at this stage the adjustment processes resulting from transition had almost been finished, and the economy had moved to a trajectory characterized by long-term growth. In such a situation, it can be assumed that labour would become scarcer while capital would become more abundant. Under these conditions, labour-saving and capitalusing technical changes could be expected. The fact that the estimates indicate the opposite directions suggests that despite more than one decade of transition, serious adjustment problems exist, including problems on the capital market. However, despite rapid changes in the capital stock, firms may still face severe capital shortages. This interpretation is supported by the low production elasticity for capital. Moreover, since food processing companies are usually located in rural areas, the integration of the rural labour market is rather limited, i.e., rural areas benefited only partially from the upswing of the economy. This interpretation also corresponds to the estimated relation of elasticity, which suggests that capital, in relation to labour, was a rather scarce factor of production for most firms.

The parameter $\sigma$ provides information about the joint variation of $u_{\mathrm{it}}$ and $v_{\mathrm{it}} \cdot \lambda$ is the relation between the variance of $u_{\mathrm{it}}$ and $v_{\mathrm{it}}$. Thus, the parameter indicates the significance of TE in the residual variation. A value larger than one suggests that variation in $u_{\mathrm{it}}$ is more pronounced than variation in the random component $v_{\mathrm{it}} .2 .6$ suggests that efficiency differences among firms are an important reason for variations in production. 
Furthermore, the estimation results show that there is a large variation in the firms' exogenous productivity levels, $a_{i}$, in the full sample (Figure 1). However, the differences among the selected industries are less pronounced. With the exception of the Dairy industry, the firms in the other groups are rather homogeneous. Moreover, the fact that all groups display about the same average fixed effect (the black dot) suggests that the large variation in the full sample is caused by a small number of companies. Since the productivity differences captured by the fixed effect are constant over time, they will not be explicitly considered in the discussion of the sources of productivity development. However, they are considered as a constant effect in the TFP comparisons between industries.

In sum, the sectors show rather similar patterns regarding processing technologies. This can only be partly explained by the fact that a joint production function was estimated, since only second order effects are not allowed to vary among the firms. However, rather comparable production elasticities across the industries indicate that, on average, the companies are affected by the same determinants from the economic and institutional environment. One of these factors concerns the ongoing transition processes and other adjustment needs in the context of EU accession.

Figure 1:

Variation of Fixed Effects among Firms (by industry)

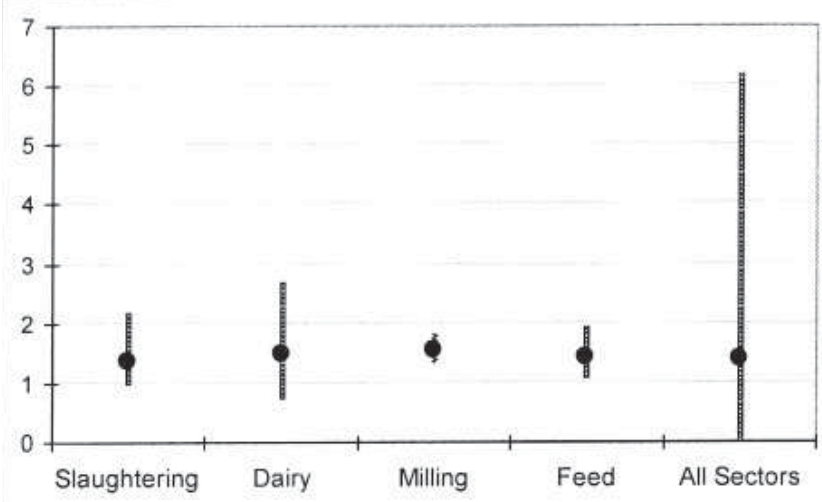

Source: own calculations.

\subsection{TFP Developments by Industry}

The information in Figure 2 is based on calculations conducted with (3) to (6). Average TFP dropped until 2001, when it started to rise steadily. In 2007, it reached the level it had in 1999. The development in the selected industry follows this pattern only conditionally. For Feed and Milling similar developments could be observed. The Dairy industry was characterized by a development that is almost opposite to that in the other industries. This sector experienced a significant drop in TFP, at a time when this indicator was already recovering in the other sectors. As a result, the Dairy industry lost the leading position, in terms of TFP, which it had reached in early 2000. In Slaughtering, TFP remained more or less constant over the period under investigation. 
Figure 2:

TFP Development in the Czech Food Processing (by industries)

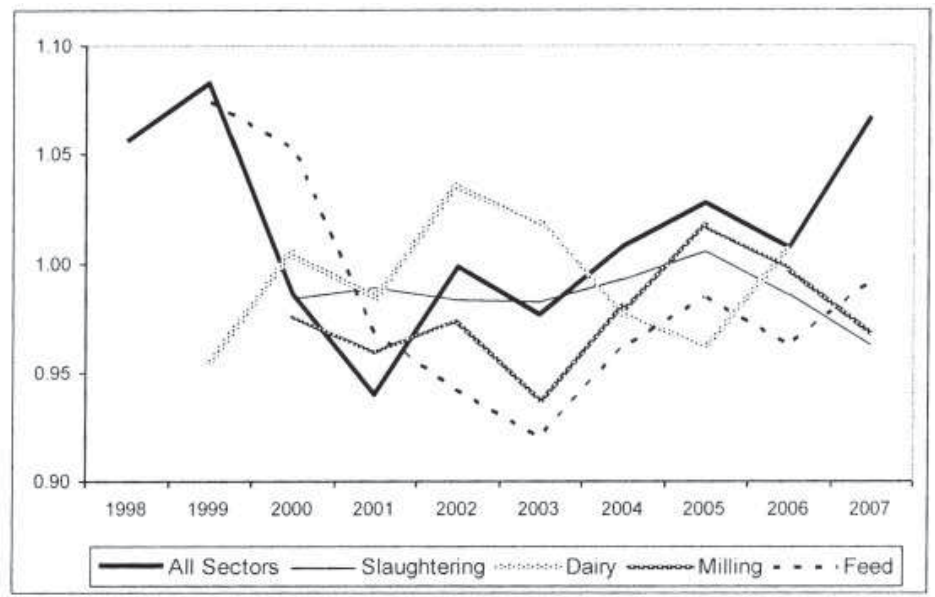

Source: own calculations.

Moreover, TFP levels in the selected industries were lower in most years than the sample average. One reason for the TFP differences is the different variations in fixed effects among industries (Figure 1). It appears that the high exogenous productivity effect estimated for some companies finds its expression in a more-than-proportional impact on TFP.

Figure 3:

Spread of TFP in Selected Sectors in the Czech Food Processing (by industry)

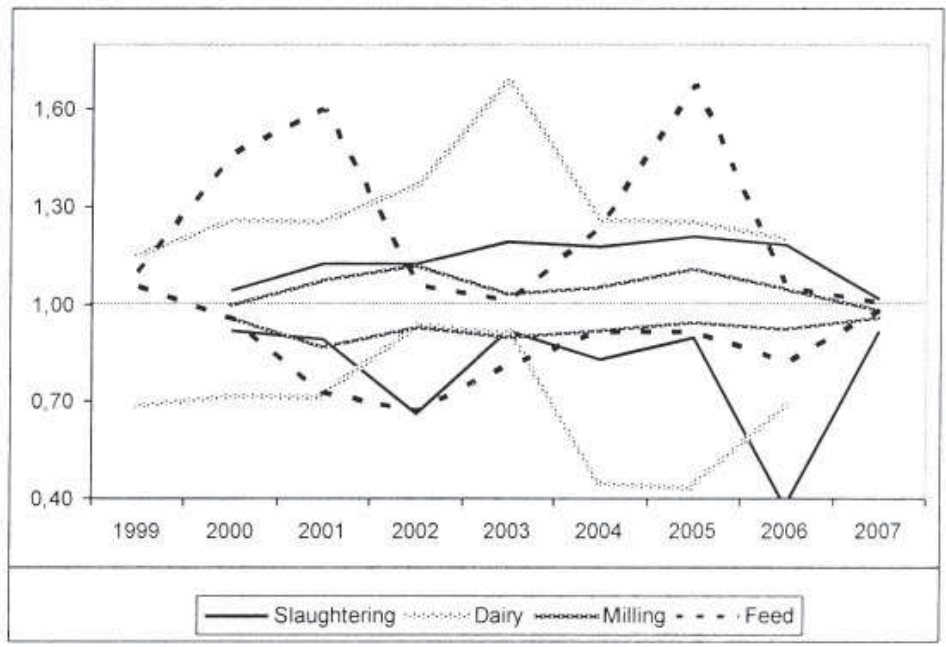

Source: own calculations. 
So far we have only discussed average TFP. Since we had an unbalanced panel, developments are affected by the entry and exit of companies, to and from a sample. It can be seen from Figure 3 that this is a severe problem. The minimum and maximum values of TFP, by sector, have fluctuated greatly over the years. However, in most years, the difference between the maximum and average value is higher than the difference between the minimum value and the average. Together with the lower-than-average TFP, this suggests a skewed distribution of firms. There are a few frontrunners in the individual sectors; however, the majority of companies only perform rather poorly. This characteristic can be observed in other transition countries as well. It also ensures that the sectors will be subject to substantial structural changes, including a high rate of exiting the market, in the coming years.

\subsection{Sources of Productivity Growth}

Figure 4 provides information on the contributions of scale, technical change and efficiency effect toward annual TFP change. Consistent with the estimates of constant returns to scale, the scale effect was rather small and contributed significantly to TFP only in certain years. The impact of technical change was negative in the first years (until 2003) and then started to have a positive impact on TFP. Interestingly, the impact of TE varied considerably, although it did decrease in the final years. Contrary to our expectations, there was no clear positive trend in the development of the efficiency effect. The reasons for this are difficult to identify. One determinant may be accession to the EU, which required additional adjustment processes (like the adoption of the acquis communautaire), especially in the year prior to 2004. The negative impact of TE from 1999 to 2003 supports this view. In this interpretation, the negative efficiency impact in 2006/05 can be regarded as random. Thus, a positive development in (transition-determined) efficiency cannot be excluded.

Figure 4:

Source of TFP Development

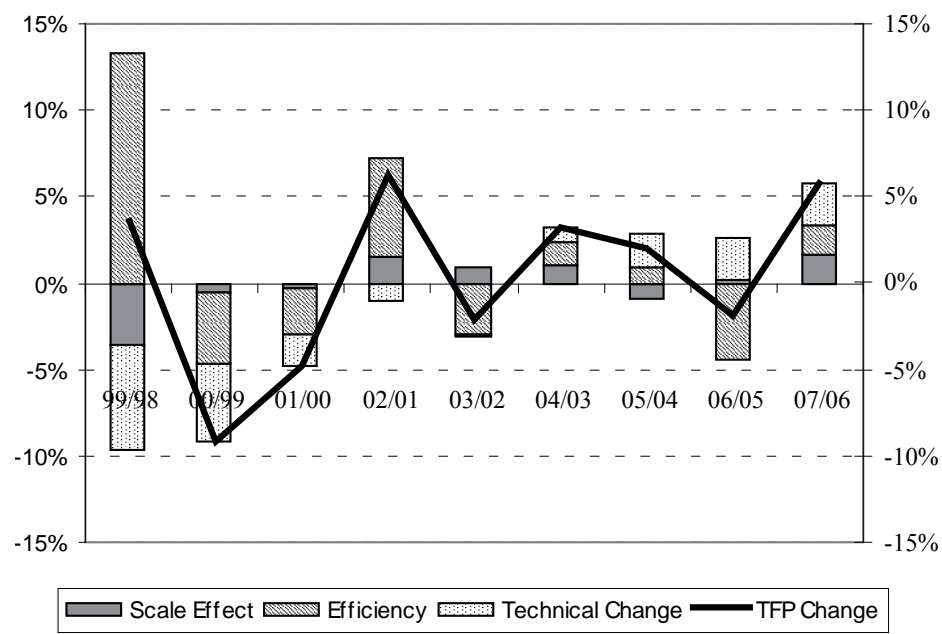

Source: own calculations. 
Figure 4 shows only aggregated development across all sectors. Figure 5 will be used to analyse how the three sources affected development in the other sectors. TCE has a similar pattern in all industries: negative in the early years and positive later on. The scale effect in the selected industries, except for Milling, was a bit more pronounced than in the whole sample. This corresponds to the higher returns to scale identified for the sectors (Table 3). Notable is the large scale effect in 2007/06 in Slaughtering. Given the reduction in the number of farms in the data set after 2006, this figure can be regarded as a bias resulting from the elimination of firms from the data set, rather than a consequence of economic factors. The same argument holds for the drop in efficiency in 2006/2005.

Another interesting result is the switch of the efficiency effect in Dairy from positive to negative. This development can be attributed to additional competition on the milk market induced by the capacity expansion of Sachsenmilk, the largest dairy processing company in Europe. The company is located in eastern Germany, close to the Czech border. It absorbs a significant amount of raw milk from Czech farmers, thereby leaving Czech dairy processors with high unused capacities.

\section{Discussion}

In this section we will concentrate on the question raised in the introduction, namely the one regarding the impact of TCE and TE on productivity developments in the Czech food processing, and whether these developments are systemic or idiosyncratic.

First, the estimates of the production function suggest that the various sectors in the food processing industry operate with rather similar production technologies. One difference concerns economies of scale, which are slightly more pronounced in Dairy than in the other sectors. The estimates indicate that the impact of technical change varies among the subgroups, with above-average impacts in Milling and a rather small influence in Dairy. Thus, with regard to SE and TCE, a fairly similar pattern could be observed across industries. Because of almost constant returns to scale, TCE has, on average, a larger impact on TFP development. However, TCE and TE represent developments on the production function $\mathrm{f}$. An inspection of the results suggests that the distribution of TFP is quite skewed towards firms with low TFP levels. In fact, efficiency differences affect TFP significantly. There is some indication that TE is affected by different sources. These include the ongoing economic transition and adjustments required by the EU accession process. The latter, in particular, might have negatively affected the performance of the food processing industry. Despite an increase in capital intensity, this input is apparently scarce in food processing a situation for companies in economic transition.

Besides this systemic effect, developments in the industries are also characterized by idiosyncratic factors. This is especially pronounced in Dairy. In this sector, an increase in competition has led to a degradation of resources, which has found its expression in a significant decrease in technical efficiency.

Since the food processing industry is an important part of the value chain and significantly determines the performance of agriculture, we may propose several policy recommendations based on the obtained results. First of all, the formulation of agrarian policy should not only take into account the character of the whole value chain, but should also be targeted on the processing and consumer stages of the value chain. 

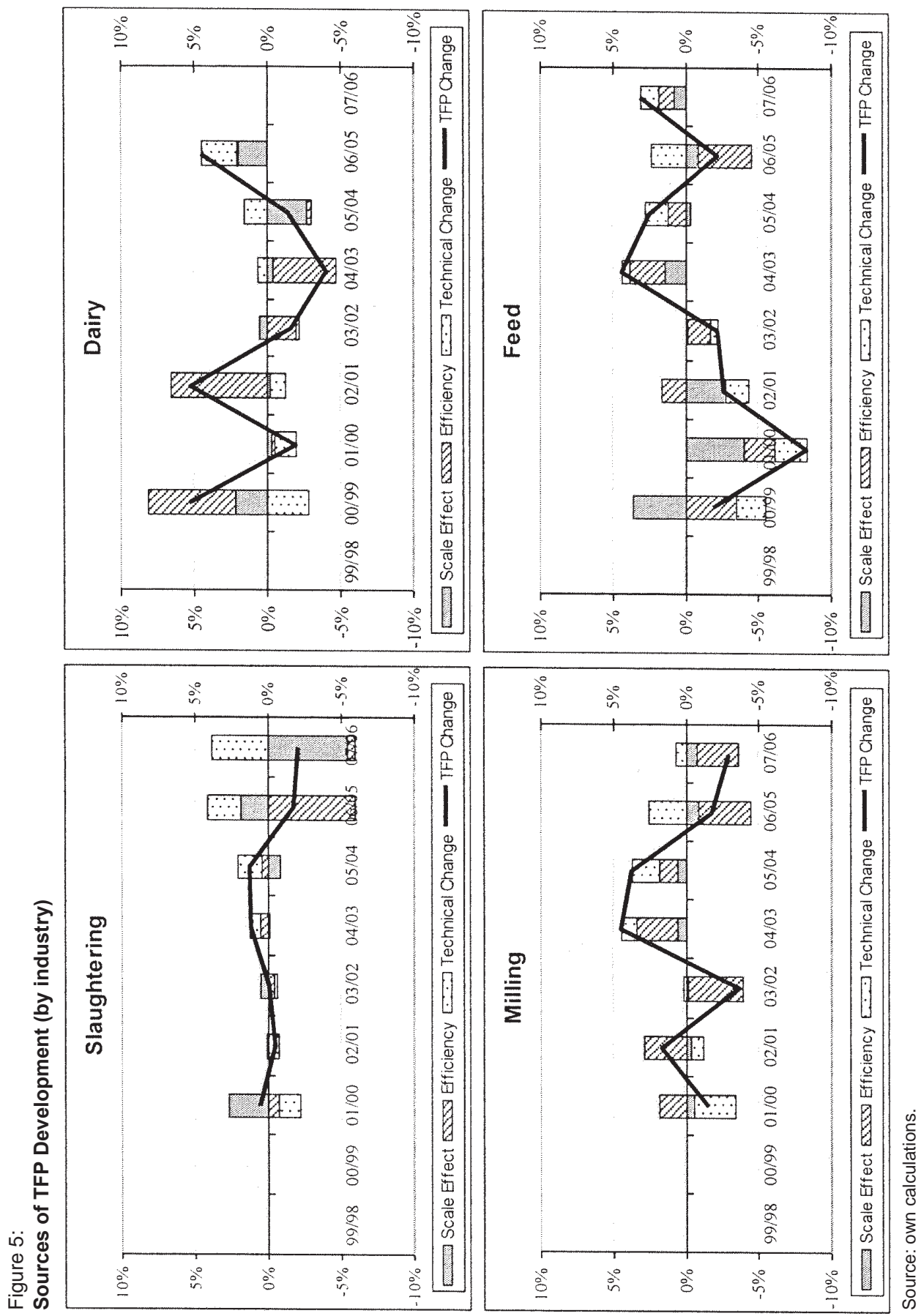
We may postulate that the competitiveness of Czech farmers depends on the competitiveness of the Czech food processing firms. Since the results identified that technical inefficiency is a significant phenomenon in the Czech food processing industry, ways of reducing the waste of resources should be found. The supports and policy tools should be sector-specific, because the food industries differ from each other. For example, the Dairy industry has significantly different characteristics and development compared to other industries. Moreover, regional differences should be considered as well (see, e.g. Bayarsaihan and Coelli 2003 and Key et al. 2008). In general, with respect to market position and the role of retailers in the value chain, vertical integration and intensive marketing of Czech producers should be supported, especially in value chains where agricultural raw materials play a central role in the production process, such as in meat and dairy value chains, for example. Furthermore, the identified problem with capital availability could be efficiently solved by programs analogous to the agricultural programs operated by SGAF (Supporting and Guarantee Agricultural and Forestry Fund). The support of capital-using and labour-saving technical changes should be of great interest, with regard to not only the competitiveness of the Czech agrarian sector internationally, but also the development of rural areas in the Czech Republic.

\section{References}

Bakucs, L. Z., Latruffe, L., Fertő, I., Fogarasi, J. (2006), "Technical Efficiency of Hungarian Farms before and after Accession." Paper prepared for presentation at Transition in Agriculture Agricultural Economics in Transition III conference Budapest, 2006 November, pp. 10-11.

Bayarsaihan, T., Coelli, T. J. (2003), "Productivity Growth in pre-1990 Mongolian Agriculture: Spiralling Disaster or Emerging Success?" Agricultural Economics 28: pp. 121-137.

Caves, D. W., Christensen, L. R., Diewert, W. E. (1982), "Multilateral Comparisons of Output, Input and Productivity using Superlative Index Numbers." Economic Journal 92: pp. 73-86.

Curtiss, J. (2002), "Efficiency and Structural Changes in Transition - a Stochastic Frontier Analysis of Czech Crop Production." Institutional Change in Agriculture and Natural Resources (12). Aachen.

Diewert, W. E. (1976), "Exact and Superlative Index Number." Journal of Econometrics 4: pp. 115-145.

Greene, W. (2002), "Fixed and Random Effects in Stochastic Frontier Models." Working Papers 02-16, New York University, Leonard N. Stern School of Business, Department of Economics.

Hockmann, H., Pieniadz, A., Goraj, L. (2007), "Modelling Heterogeneity in Production Models: Empirical Evidence from Individual Farming in Poland." Economics of Polish Agriculture, Selected Papers. 2/2007, pp. 55-71.

Jansik, C. (2002), "Determinants and Influence of Foreign Direct Investments in the Hungarian Food Industry in a Central and Eastern European Context: An Application of the FDI-Concentration Map Method." MTT Taloustutkimus. Julkaisuja.

Key, N., McBride, W., Mosheim, R. (2008), "Decomposition of Total Factor Productivity Change in the U.S. Hog Industry." Journal of Agricultural and Applied Economics 40: pp. 137-149.

Kumbhakar, S., Hjalmarsson, L. (1993), "Technical Efficiency and Technical Progress in Swedish Dairy Farms.” In H. Fried, K. Lovell, Schmidt, S., eds., The Measurement of Productive Efficiency: Techniques and Applications. New York.

Munroe, D. (2001), "Economic Efficiency in Polish Peasant Farming: An International Perspective." Regional Studies, Vol. 35(5), pp. 461- 471.

Wandel, J., Hartmann, M. (1999), "Food Processing and Distribution in Transition Economies: Problems and Perspectives." Studies on the Agricultural and Food Sector in Central and Eastern Europe, Vol. 3, Halle (Saale). 